\section{Electrotransport of ${ }^{22} \mathrm{Na}$ and of ${ }^{195} \mathrm{Au}$ in Liquid Sodium}

\section{T. Persson and A. Lodding}

Physics Department, Chalmers University of Technology, Gothenburg, Sweden

(Z. Naturforsch. 28 a, 1971-1972 [1973]; received October 22, 1973)

The mobilities of radioactive $\mathrm{Na}$ and $\mathrm{Au}$ tracers under electric current in liquid $\mathrm{Na}$ have been studied. In both cases the tracer is enriched at the anode, but the mobility of the impurity is by about two orders of magnitude greater than that of the Na tracer. The Haeffner-effect, for the first time studied with a radioactive isotope, yielded an "isotope factor" $x \simeq 0.2$ at $180^{\circ} \mathrm{C}$, of the same order of magnitude as in $\mathrm{K}$ and $\mathrm{Rb}$. The effective charge number $Z_{\mathrm{exp}}^{*}$ for the electrotransport of $\mathrm{Au}$ in $\mathrm{Na}$ decreases from about - 12 at $100{ }^{\circ} \mathrm{C}$ to -7.5 at $270^{\circ} \mathrm{C}$.

Isotope electrotransport in liquid metals (Haeffner-effect ${ }^{1,2}$ ) has hitherto only been measured in such metals where the existence of several stable isotopes permits mass spectrometric analysis. Quantitative results have been obtained i. a. for $\mathrm{Rb}$ and $\mathrm{K}$. We decided to study the effect also in $\mathrm{Na}$, and for the first time utilize a radioactive isotope, i. e. by measuring the migration velocity of ${ }^{22} \mathrm{Na}$ at infinite dilution, relative to the matrix atoms with the atom mass 23 . The relative mass difference $(1: 23)$ is here of the same order of magnitude as when using the stable isotopes of $\mathrm{K}(1: 20)$, and although the available radioactive counting technique was not expected to give as good accuracy as the well established mass spectrometric analysis, at least semiquantitative results were envisaged.

A capillary arrangement was used, of a type described in several earlier publications ${ }^{1-3}$. The duration of each run was chosen so as not to approach the steady state in the $20 \mathrm{~cm}$ long capillary; however, in the runs with the maximal current density (9 A in $0.6 \mathrm{~mm}$ i. d. capillaries) a correction for convection effects had to be made. The need of this was realized when discovering that the specific activity far away from the anode did not, as theoretically expected, remain unchanged, but showed a certain depletion of the tracer. The correction, based on the difference in specific activity between the depleted region and reference samples. amounted to some $25 \%$ and introduced an extra uncertainty margin of about $15 \%$ in these runs.

The velocity of the tracer relative to the bulk was determined ${ }^{3}$ from

$$
\Delta v=(l / t)\left(\Delta A / A_{0}\right),
$$

Reprint requests to Dr. A. Lodding, Arkitektvägen 6 B, S-43080 Hovås, Schweden. where $t$ is the duration of the run, $l$ is the length along the capillary from the anode to a point $\mathrm{P}$ chosen where the tracer activity remained unchanged throughout the experiment; $A_{0}$ is the total tracer activity in that capillary portion before, and $A_{0}+\Delta A$ after the experiment. The Haeffner-effect is then expressed by the magnitude of the "mass factor" 1,2 ,

$$
\varkappa=\left(\Delta v / v_{\mathrm{e}}\right) /(\Delta M / M),
$$

where $\Delta M$ is the isotope mass difference, $M$ the atom mass of the mixture (here that of the matrix), and

$$
v_{\mathrm{e}}=(D / k T) E e,
$$

$e$ being the electronic charge, $k$ Boltzmann's constand, $D$ the diffusion coefficient ${ }^{4}, T$ abs. temperature and $E$ the field strength.

The results are shown in Table 1. The accuracy was limited by the fluctuations in the counting sensitivity of the hollow-crystal single channel analyzer and by the uncertainty (particularly in the samples exhibiting convection effects, see above) concerning the original specific activity. In spite of the wide margins of error, it can be concluded from Table 1 that the mass factor is of the order of 0.5 at the m.p. and decreasing with rising temperature. In Table 1, a comparison is made with Haeffner-effect data of the other two alkali metals, taken from Ref. ${ }^{2}$ and corrected according to the latest measurements of $\mathrm{D}$ in these metals ${ }^{4}$.

\begin{tabular}{lll}
\hline Metal & $\begin{array}{l}\text { Tempera- } \\
\text { ture, }{ }^{\circ} \mathrm{C}\end{array}$ \\
\hline $\mathrm{Na}$ & 137 & $0.40 \pm 0.21$ \\
$\mathrm{Na}$ & 162 & $0.26 \pm 0.11$ \\
$\mathrm{Na}$ & 164 & $0.19 \pm 0.09$ \\
$\mathrm{Na}$ & 224 & $0.16 \pm 0.09$ \\
$\mathrm{Na}$ & 225 & $0.13 \pm 0.06$ \\
$\mathrm{Na}$ & 226 & $0.15 \pm 0.08$ \\
$\mathrm{~K}$ & 100 & 0.31 \\
$\mathrm{~K}$ & 200 & 0.29 \\
$\mathrm{Rb}$ & 100 & 0.49 \\
$\mathrm{Rb}$ & 200 & 0.41 \\
\hline
\end{tabular}

Table 1.

Isotope Factor of HaeffnerEffect in Liquid Alkali Metals.

As a part of a systematic investigation of impurity atom transport in liquid alkali metals ${ }^{3-5}$ we also studied the electrotransport of ${ }^{195} \mathrm{Au}$ in liquid sodium, employing the same experimental set-up as recently ${ }^{3}$ for ${ }^{22} \mathrm{Na}$ in $\mathrm{K}$ and for the Haeffner-effect study reported above. Again $\Delta v$ was obtained via Equation (1). However, as the velocities of the impurity relative to the matrix here were of the order of $1 \mathrm{~cm} /$ hour, which is more than a hundred times faster than for ${ }^{22} \mathrm{Na}$ in $\mathrm{Na}$, the results could be ob- 
tained much more accurately. Some of the runs required a correction for convection effects, similar to that mentioned above, but the extra error introduced was less than $\pm 5 \%$. The results are listed in Table 2. The "experimental charge number" is defined as

$$
Z_{\text {exp }}^{*}=-\Delta v / v_{\mathrm{e}}
$$

(i. e. negative as the tracer moves along with the electrons). The diffusion coefficients of $\mathrm{Au}$ in $\mathrm{Na}$ have been measured recently ${ }^{6}$.

The magnitudes as well as the temperature dependence of $Z_{\exp }^{*}$ are very similar to the behaviour ${ }^{3}$ of $\mathrm{Na}$ in $\mathrm{K}$, where the experimental charge number ranges from about -12 at the m.p. to -5 at $310^{\circ} \mathrm{C}$. A discussion along similar lines as in Ref. ${ }^{3}$ leads to the conclusion that the effective excess resistivity $\varrho_{\text {eff }}^{*}$ for $\mathrm{Au}$ in $\mathrm{Na}$ is close to $1.2 \mu \Omega \mathrm{cm} / \%$ impurity

1 A. Lodding, Gothenburg Stud. Phys. 1 [1961].

2 A. Lodding, J. Phys. Chem. Solids 28, 557 [1967].

3 C. Roxbergh, T. Persson, and A. Lodding, Phys. Chem. Liq. 4, 1 [1973].

4 S. J. Larsson, C. Roxbergh, and A. Lodding, Phys. Chem. Liq. 3, 137 [1972].
Table 2. Experimental Charge Numbers of Electrotransport, ${ }^{195} \mathrm{Au}$ in Liquid Na.

\begin{tabular}{llll}
\hline $\begin{array}{c}\text { Tempera- } \\
\text { ture, }{ }^{\circ} \mathrm{C}\end{array}$ & $-Z_{\text {exp }}^{*}$ & $\begin{array}{c}\text { Tempera- } \\
\text { ture, }{ }^{\circ} \mathrm{C}\end{array}$ & $-Z_{\text {cxp }}^{*}$ \\
\hline 106 & $11.8 \pm 0.6$ & 192 & $9.3 \pm 0.4$ \\
119 & $10.7 \pm 0.9$ & 210 & $9.6 \pm 0.7$ \\
129 & $10.4 \pm 0.8$ & 236 & $8.2 \pm 0.6$ \\
142 & $11.0 \pm 0.8$ & 253 & $8.2 \pm 0.3$ \\
155 & $10.2 \pm 0.6$ & 262 & $9.5 \pm 0.6$ \\
172 & $10.7 \pm 0.9$ & 272 & $7.4 \pm 0.4$ \\
185 & $9.4 \pm 0.7$ & & \\
\hline
\end{tabular}

(cf. 1.3 for $\mathrm{Na}$ in $\mathrm{K}$ ), with practically no temperature dependence.

This work was supported by the Swedish Board of Technical Development. We thank Fil. lic. S. J. Larsson and Fil. mag. S. E. Eriksson for stimulating discussions.

5 T. Persson and S. J. Larsson, Z. Naturforsch. 28 a, 117 [1973].

${ }^{6}$ T. Persson, S. J. Larsson, and A. Lodding, to be published in Phys. and Chem. Liquids. 